\title{
37 THE COMPARATIVE EFFECTIVENESS OF ISOTONIC AND ISOKINETIC STRENGTH TRAININGS ON QUADRICEPS PEAK TOROUE
}

Hitanshu Agnihotri Department of Physiotherapy, Maharishi Markandeshwar University, Mullana, Ambala, Haryana, India

10.1136/bjsm.2010.078725.37

The present study compares the effectiveness of isotonic and isokinetic exercises on peak torque of quadriceps in 45 healthy young males. The subjects were randomly assigned into three groups ( $\mathrm{n}=15)$ : group $\mathrm{A}$ - isotonic group, group $\mathrm{B}$ - isokinetic group, group $\mathrm{C}$ - control group. Peak torque of quadriceps at velocities of 220 and $100 \%$ s was tested twice with a gap of 4 weeks using isokinetic dynamometer. Isotonic protocol included three sets of 10 repetitions at 50\% $10 \mathrm{RM}, 75 \% 10$ RM and 100\% 10 RM. The isokinetic protocol consisted of one set of 10 repetitions at velocities of $220,160,100$ and $40 \%$ each. Each exercise protocol was performed thrice a week for 4 weeks with 1-min rest interval. The subjects in the control group were not prescribed any kind of exercise training. Paired $\mathrm{t}$ test showed significant changes at $220 \% \mathrm{~s}(\mathrm{t}=4.62, \mathrm{p}<0.001)$ and $100 \%(\mathrm{~s}=2.49, \mathrm{p}<0.05)$ in group $\mathrm{A}$, at $220 \%(\mathrm{t}=3.42$, $p<0.05)$ in group $B$ and non-significant changes at $220 \%$ $(t=2.02, p>0.05)$ and $100 \% s(t=0.82, p>0.05)$ in group C. Posttest one-way analysis of variance revealed significant changes at $220 \% \mathrm{~s}(\mathrm{~F}=4.47, \mathrm{p}<0.05)$. Isotonic exercises were found to be more effective than isokinetic exercises in increasing the peak torque at high velocity. 